\title{
Titrating Optimal Dose of Osmotic-Controlled Release Oral Delivery (OROS)-Methylphenidate and Its Efficacy and Safety in Korean Children with ADHD: A Multisite Open Labeled Study
}

\author{
Dong-Ho Song ${ }^{1}$, Soul Choi', Yoo Sook Joung ${ }^{2}$, Eun Hye Ha ${ }^{3}$, Boong-Nyun Kim4, \\ Yee-Jin Shin ${ }^{1}$, Dongwon Shin ${ }^{5}$, Hee Jeong Yoo ${ }^{6}$, Keun-Ah Cheon ${ }^{1 凶}$ \\ ${ }^{1}$ Department of Child and Adolescent Psychiatry, Yonsei University College of Medicine, Seoul, Republic of Korea \\ ${ }^{2}$ Department of Psychiatry, Sungkyunkwan University School of Medicine, Seoul, Republic of Korea \\ ${ }^{3}$ Department of Child Welfare, Sookmyung Women's University, Seoul, Republic of Korea \\ ${ }^{4}$ Department of Child and Adolescent Psychiatry, Seoul National University Hospital, Seoul, Republic of Korea \\ ${ }^{5}$ Department of Psychiatry, Sungkyunkwan University School of Medicine, Kangbuk Samsung Hospital, Seoul, Republic of Korea \\ ${ }^{6}$ Department of Child and Adolescent Psychiatry, Seoul National University Bundang Hospital, Seongnam, Republic of Korea
}

Objective This study was aimed to determine effectiveness and tolerability of Osmotic-controlled Release Oral delivery (OROS) methylphenidate (MPH) and its optimal dose administered openly over a period of up to 12 weeks in drug naïve Korean children with ADHD. Methods Subjects $(n=143)$, ages 6 to 18-years, with a clinical diagnosis of any subtype of ADHD were recruited from 7 medical centers in Korea. An individualized dose of OROS-MPH was determined for each subject depending on the response criteria. The subjects were assessed with several symptom rating scales in week 1, 3, 6, 9 and 12 .

Results 77 of 116 subjects $(66.4 \%)$ achieved the criteria for response and the average of optimal daily dose for response was to $30.05 \pm 12.52 \mathrm{mg}$ per day $(0.90 \pm 0.31 \mathrm{mg} / \mathrm{kg} / \mathrm{d})$ at the end of the study. Optimal dose was not significantly different between ADHD subtypes, whereas, significant higher dose was needed in older aged groups than younger groups. The average of optimal daily dose for response for the subjects aged above 12 years old was $46.38 \pm 15.52$ per day $(0.81 \pm 0.28 \mathrm{mg} / \mathrm{kg} / \mathrm{d}$ ) compared to younger groups ( $<<0.01$ ). No serious adverse effects were reported and the dose did not have a significant effect on adverse effects.

Conclusion Optimal mean dose of OROS-MPH was significantly different by age groups. Higher dose was needed in older aged groups than younger groups. Effectiveness and tolerability of OROS-MPH in symptoms of ADHD is sustained for up to 12 weeks.

Psychiatry Investig 2012;9:257-262

Key Words ADHD, OROS-MPH, Optimal dose.

\section{INTRODUCTION}

ADHD, one of the most frequently diagnosed neurobehavioral diseases, is characterized by developmentally inappropriate attention deficit, hyperactivity, impulsivity. ${ }^{1,2}$ The number of ADHD patient is estimated up to 5-10\% among child-

Received: December 12, 2011 Revised: May 1, 2012

Accepted: May 10, 2012 Available online: September 6, 2012

$\triangle$ Correspondence: Keun-Ah Cheon, MD, PhD

Department of Child and Adolescent Psychiatry and Institute of Behavioral Science in Medicine, Severance Children's Hospital, Yonsei University College of Medicine, 50 Yonsei-ro, Seodaemun-gu, Seoul 120-752, Republic of Korea Tel: +82-2-2228-1633, Fax: +82-2-313-0891

E-mail: kacheon@yuhs.ac, kacheon@gmail.com

(a) This is an Open Access article distributed under the terms of the Creative Commons Attribution Non-Commercial License (http://creativecommons.org/licenses/bync/3.0) which permits unrestricted non-commercial use, distribution, and reproduction in any medium, provided the original work is properly cited. ren worldwide, and approximately $70 \%$ of them persists until adolescence. $^{3}$ It causes learning and behavioral problems, peer difficulties, low self-esteem, risk of adult crime and substance abuse. ${ }^{4,5}$

Currently, the stimulant medications, such as methylphenidate, are most used medications as first line treatment for ADHD children. Although, methylphenidate has established better efficacy over other behavioral and psychosocial treatments showing $70 \%$ of positive treatment response, ${ }^{6}$ only half of those diagnosed as ADHD receive treatment, with fewer than one third accessing specialty services ${ }^{7}$ and considerable variation in stimulant medication use among children with $\mathrm{ADHD}$ has been documented through researches. Disparities in use have been observed on biological factors such as age, gender, race/ethnicity, and cultural factors like community 
socioeconomic characteristics, including parent's attitude, stigma, clinician's own training background and clinical experience. $^{8-10}$

Lack of knowledge, stigma, concerns about the increasing use of psychotropic medications, and cost considerations have been cited as explanations for low rates of treatment seeking, adherence, and positive outcome. Additionally, parental beliefs that medication is inappropriate for major emotional or behavioral problems in childhood, contribute to low treatment rates of psychostimulants, also. ${ }^{11}$

In cross cultural aspect, the treatment rates for behavioral disorders have reported to be lower in non-Western children as compared to Western children. ${ }^{12}$ As regard of Asian cultural society, we suggest cultural background would affect dosing and titration of methylphenidate in treating ADHD children, thus determination of the optimal dose for ADHD children would be more delicate in Korea, like Asian countries.

The Osmotic-controlled Release Oral delivery (OROS)-methylphenidate of extended release tablet has been recently developed to eliminate the inconvenience of multiple dosing of immediate-release methylphenidate. ${ }^{13}$ Ever since the first release of OROS-MPH in Korea in 2003, OROS-MPH use has steadily increased to 53,425 of children with ADHD were prescribed with OROS-MPH in 2006. ${ }^{14}$ However, cultural influences and media's reports have a great impact on OROS-MPH use, clinically. In terms of that point, it is important to explore moderating factors associated with titration and dosing of methylphenidate in a Korean population.

The hypothesis of this study was that the optimal dosage of OROS-MPH would be determined by age, subtypes of ADHD, symptom severity and severity of adverse effects.

The aim of this study was to examine the pattern of dose titration and optimal dose of OROS-MPH, and to evaluate the relationship between the optimal dose and associated clinical issues including tolerability, ADHD subtype and symptom severity in Korean subjects with ADHD.

\section{METHODS}

\section{Subjects}

We conducted our trial on 143 children, aged from 6 to 18year-old who were diagnosed as ADHD, based on clinical evaluation using Diagnostic and Statistical Manual of Mental disorder, Fourth Edition (DSM-IV) criteria, confirmed by structured interview (using the Kiddie Schedule for Affective Disorders and Schizophrenia) ${ }^{15}$ All subjects were not exposed to OROS-MPH within 3 months.

\section{Exclusion criteria}

The children, suffered from the following disease, were not included in this procedure; mental retardation (IQ under 70), Tourette syndrome, chronic tic disorders, psychotic disorders, seizure disorders, brain injury, pervasive developmental disorders, severe medical or surgical disorders and planning to start or change behavioral therapy as well as those children who were taking selective serotonin reuptake inhibitor and antipsychotics within 4 weeks.

\section{Procedures}

Each subject's parents were required to give signed informed consent. Written approval of the study design was obtained from the institutional review board for all participating centers before initiation of the study. This multisite study (7 sites) consisted of 24-hour washout period and 12-week open-labeled dose titration period. After a 24-hour washout period during which all previous drugs for ADHD were discontinued, subjects underwent a series of baseline assessments; Korean-Wechsler Intelligence Scale for Children (K-WISC-II), vital signs, medical history, physical examination, laboratory test, electrocardiography. Subjects then entered the open-label dose titration phase. An individualized dosage of OROS-MPH was determined for each subject based on clinical evaluation performed by child psychiatrists in each site. The criteria of response, defined as Korean ADHD Rating Scale (K-ARS) $<18^{16}$ and Clinical Global Impression-Improvement (CGI-I) 6 or $7 .{ }^{17}$ If the psychiatrist judge the criteria of response was not met for the child, the subject received increased dose of OROS$\mathrm{MPH}, 18 \mathrm{mg} / \mathrm{d}$ or $27 \mathrm{mg} / \mathrm{d}$. Subjects were evaluated on week 1 , week 3 , week 6, week 9 and week 12 . CGI-I, Side-effects rating scale (SRS), Adverse events, K-ARS were assessed at every visits.

\section{Study measures}

\section{Korean ADHD Rating Scale}

The Korean ADHD Rating Scale consists of 18 items that assess DSM-IV criteria for inattention and hyperactivity. Items are scored on a 4-point scale (from 0 , never or rarely, to 3 , very often). The Korean version was found to demonstrate discriminant validity ${ }^{18}$ and has been used in treatment studies. ${ }^{19}$ ADHD is suspected if total score is above 19.

\section{Clinical Global Impression-improvement}

The investigator-rated global assessment of effectiveness uses a 7-point scale (from 7, very much worse, to 1 , very much improved) to evaluate the response of the subject to the current treatment.

\section{Side-effects Rating Scale}

Side-effects Rating Scale, developed by Barkley, ${ }^{20}$ consists of 
17 most commonly reported adverse effects of methylphenidate. Each item is rated on a 10-point scale (0: none through the past week, to 9: very severe).

\section{Statistical analysis}

Demographic characteristics were summarized in descriptive statistics. Repeated measures analyses of variance or multivariate analyses of variance were used to evaluate treatment effectiveness for ADHD subtype. Pearson correlation was performed to examine the relationship between dose and SRS, K-ARS scores. Statistical significance was indicated by p-values of 0.05 or less. All statistics were demonstrated under SPSS 12.0.

\section{RESULTS}

\section{Diagnostic and descriptive information}

A total of 143 children were participated in the study from March 1, 2006 to September 31, 2006, at different 6 centers in South Korea. Twenty-seven of children could not complete the procedure of treatment for the following reasons: noncompliance of medication (12 subjects, $44.4 \%$ ), adverse effects (8 subjects, $29.6 \%$ ), follow up loss (6 subjects, $22.2 \%$ ) and others ( 1 subject, $3.7 \%$ ).

The demographic and baseline characteristics of subjects are given in Table 1. The average age of the participants was $9.36 \pm 2.4$ years and most of participants were male. 128 participants were drug naïve, 10 of them had received MPH treatment (Immediate Release MPH) and others were taking non MPH medications such as desmopressin, topiramate, prazocin, hydroxyzine, clenbutenol.

\section{Dosing pattern}

Of the 116 subjects who successfully completed the study, 77 (66.4\%) subjects achieved the criteria for response (K-ARS $<18$ and CGI-I 6 or 7). The average total daily dose for subjects who responded was $30.05 \pm 12.52 \mathrm{mg}$ per day $(0.90 \pm 0.31$ $\mathrm{mg} / \mathrm{kg} / \mathrm{d}$ ). The optimal dosage for the subjects in this study was regarded as the dosage which was effective (according to above response criteria) and tolerable (no and minimal adverse effects) in every single child. The titrating procedure was performed flexible and naturalistic depending on individual response and tolerability. Their individualized dosage of OROS methylphenidate were 25 subjects $(32.5 \%)$ at $18 \mathrm{mg}$, 25 subjects (32.5\%) at $27 \mathrm{mg}, 13$ subjects (16.9\%) at $36 \mathrm{mg}, 8$ subjects (10.4\%) at $45 \mathrm{mg}, 4$ subjects $(5.2 \%)$ at $54 \mathrm{mg}$, and 2 subjects $(2.6 \%)$ at $72 \mathrm{mg}$. The average daily dose increased from $19.20 \pm 3.11 \mathrm{mg}$ per day $(0.64 \pm 0.18 \mathrm{mg} / \mathrm{kg} / \mathrm{d})$ at week 1 to $34.13 \pm 13.80 \mathrm{mg}$ per day $(1.03 \pm 0.3318 \mathrm{mg} / \mathrm{kg} / \mathrm{d})$ at the end of 12 weeks of dosing (Figure 1).
Table 1. Demographics and baseline clinical characteristics $(\mathrm{N}=$ 143)

\begin{tabular}{|c|c|}
\hline Characteristics & Subjects, N (\%) \\
\hline \multicolumn{2}{|l|}{ Age (years) } \\
\hline $0-9$ & $74(0.8)$ \\
\hline $9-12$ & $46(0.8)$ \\
\hline $12<$ & $23(1.2)$ \\
\hline Mean (SD) & $9.36(2.4)$ \\
\hline \multicolumn{2}{|l|}{ Sex } \\
\hline Male & $121(84.6)$ \\
\hline Female & $22(15.1)$ \\
\hline \multicolumn{2}{|l|}{ ADHD subtype } \\
\hline Inattentive predominant & $49(34.3)$ \\
\hline Hyperactive-impulsive & $9(6.3)$ \\
\hline Combined & $50(35.4)$ \\
\hline Not otherwise specified & $35(24.5)$ \\
\hline \multicolumn{2}{|l|}{ Comorbidity } \\
\hline Tic disorder & $12(7.0)$ \\
\hline Any anxiety disorder & $7(3.9)$ \\
\hline Depression & $6(4.1)$ \\
\hline ODD/Conduct disorder & $39(27.3)$ \\
\hline \multicolumn{2}{|l|}{ Previous pharmacotherapy } \\
\hline None & $128(89.5)$ \\
\hline Non-MPH & $5(3.5)$ \\
\hline IR-MPH & $10(6.9)$ \\
\hline Weight (kg) & $36.9(14.9)$ \\
\hline Height $(\mathrm{cm})$ & $137.3(15.1)$ \\
\hline IQ Mean (SD) & $108.13(15.3)$ \\
\hline
\end{tabular}

ADHD: attention-deficit/hyperactivity disorder, ODD: oppositional defiant disorder, MPH: methylphenidate, IQ: intelligence quotient

\section{Different treatment response in ADHD subtype}

Of the 116 children who completed the study, twenty seven (33.6\%) subjects received a diagnosis of ADHD inattentivepredominant type, twenty eight (36.2\%) subjects were combined type, three (5.2\%) were hyperactive-impulsive type and nineteen $(25.5 \%)$ subjects were not otherwise specified type. There was no difference in mean daily dose and weight/dose between subtypes on ANOVA.

\section{Safety and tolerability}

The majority of adverse events reported during the study were judged to be mild. Of the 143 children treated in the study, 121 children (84.6\%) reported at least one adverse event. Adverse events that were suspected to be treatment-related and occurred in $\geq 1 \%$ of subjects at any time during the 12 week period are presented in Table 2. Eight subjects discontinued study medication prematurely because of adverse ev- 


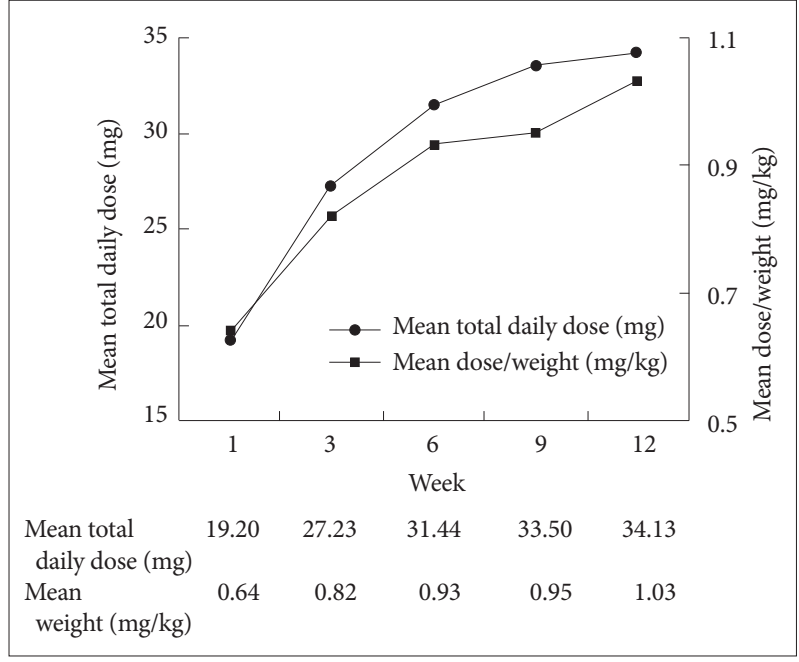

Figure 1. Average daily dose of OROS methylphenidate by week. OROS: Osmotic-controlled Release Oral delivery.

Table 2. Adverse events related to study medication reported by $\geq 1 \%$ of the total participants $(\mathrm{N}=143)$

\begin{tabular}{lc}
\hline \multicolumn{1}{c}{ Event } & Subjects, N (\%) \\
\hline Anorexia & $104(30.95)$ \\
Insomnia & $44(13.10)$ \\
headache & $30(8.93)$ \\
Abdominal pain & $20(5.95)$ \\
Dizziness & $15(4.46)$ \\
Anxiety & $12(3.57)$ \\
Nightmare & $10(2.97)$ \\
Stomach ache & $9(2.68)$ \\
Irritability & $9(2.68)$ \\
Nervousness & $9(2.68)$ \\
Nausea & $9(2.68)$ \\
Tics & $7(2.08)$ \\
Somnolence & $6(1.79)$ \\
Depression & $5(1.49)$ \\
Weight loss & $4(1.19)$ \\
\hline
\end{tabular}

ents. These events included loss of appetite, anorexia, tic, seizure, abdominal pain and headache. There was a significant difference in mean changes for systolic, diastolic blood pressure and heart rate between baseline and the end of the openlabel phase. Systolic BP increased from $105.29 \pm 12.65 \mathrm{~mm} \mathrm{Hg}$ to $108.39 \pm 70.92 \mathrm{~mm} \mathrm{Hg}(\mathrm{p}=0.001)$, diastolic $\mathrm{BP}$ from $66.85 \pm$ $10.12 \mathrm{~mm} \mathrm{Hg}$ to $70.92 \pm 10.47 \mathrm{~mm} \mathrm{Hg}(\mathrm{p}=0.001)$ and heart rate from $82.68 \pm 14.63 / \mathrm{min}$ to $89.06 \pm 14.83 / \mathrm{min}(\mathrm{p}=0.001)$. No significant changes were observed on EKG. Mean absolute weight decreased over the course of the study (baseline 36.91 \pm $14.97 \mathrm{~kg}$ vs. endpoint $35.67 \pm 14.18 \mathrm{~kg}$ ).

To examine side effects of OROS-MPH dose, we compared weekly SRS scores. Total SRS scores decreased though out
Table 3. Correlation between optimal dose and SRS in the subjects who responded to OROS-MPH $(\mathrm{N}=77)$

\begin{tabular}{lccc}
\hline & Dose & Dose/Weight & Baseline SRS \\
\hline Dose/Weight (r) & $0.357^{* *}$ & & \\
Baseline SRS (r) & 0.057 & 0.207 & \\
Endpoint SRS (r) & -0.203 & -0.019 & $0.446^{* *}$ \\
\hline
\end{tabular}

By Pearson correlation analysis. *correlation significant at the 0.05 level, **correlation significant at the 0.001 level. OROS-MPH: Osmoticcontrolled Release Oral delivery methylphenidate, SRS: Side-effects Rating Scale, r: Pearson correlation coefficient (ranged from -1.0 to 1.0)

the course. OROS-MPH dose did not have a significant effect on SRS total score $(\mathrm{F}=2.18, \mathrm{p}=0.074)$, however, in specific items of SRS, only insomnia and abdominal pain remained without a significant decrease $(\mathrm{t}=-0.690, \mathrm{t}=2.154)$. The results show that adverse effects are less likely to be reported as treatment proceeds, unrelated to the dose of OROS-MPH.

\section{Adverse effects and optimal dose}

On Pearson's product moment correlation coefficient, there was no significant relationship between dose and SRS scores at baseline and endpoint in whole subjects $(\mathrm{n}=143)$. The same result was observed in dose/weight and SRS scores of baseline and endpoint, also. Therefore, no correlation was found between the optimal dose and severity of adverse effects (Table 3).

\section{Different optimal dosage by age in responded group}

The subjects who responded to OROS-MPH were divided into 3 groups by age; below 9 , between 9 and 12, and above 12 . On ANOVA mean dose and mean weight dose showed statistically different between 3 groups. Comparing the differences between the groups by post hoc test, the mean dose of age below 9 was lower than age above 12, age between 9 and 12 was also younger than age above 12 , and age below 9 was lower than between 9 and 12. The mean dose/weight of age below 9 was significantly higher than those of age between 9 and 12 , and above $12(\mathrm{~F}=5.584, \mathrm{p}<0.01)$ (Table 4).

\section{Correlation between ADHD symptom severity and OROS-MPH dose}

There were some significant relationships reported between variables using Pearson's product moment correlation coefficient in total subjects ( $n=143)$ (Table 5). There was a highly significant and positive correlation between dose and baseline K-ARS scores ( $\mathrm{r}=0.275, \mathrm{p}=0.001)$ and also a positive correlation between dose and endpoint K-ARS scores $(r=0.365$, $\mathrm{p}=0.001$ ). Dose/weight was found to have a significant positive correlation with only baseline K-ARS scores ( $r=0.233$, $\mathrm{p}=0.041$ ). We found that dose and dose/weight increased depending on ADHD symptom severity. 
Table 4. Mean dose in each age group of the subjects who responded to OROS-MPH $(\mathrm{N}=77)$

\begin{tabular}{|c|c|c|c|c|c|}
\hline & $\begin{array}{l}\text { Below } 9 \\
(\mathrm{~N}=40)\end{array}$ & $\begin{array}{l}\text { Between } 9 \text { \& } 12 \\
\quad(\mathrm{~N}=24)\end{array}$ & $\begin{array}{c}\text { Above } 12 \\
(\mathrm{~N}=16)\end{array}$ & p-value & Post Hoc test \\
\hline Mean dose, mg (SD) & $25.43(8.12)$ & $28.9(8.79)$ & $46.38(15.52)$ & $0.000^{* *}$ & $\begin{array}{l}\text { Below } 9<\text { Above } 12, \\
\text { Btw } 9 \text { and } 12<\text { Above } 12 \\
\text { Below } 9<\text { Btw } 9 \text { and } 12\end{array}$ \\
\hline Mean dose/weight & $1.01(0.32)$ & $0.78(0.24)$ & $0.81(0.28)$ & $0.01^{*}$ & Below $9>$ Between 9 and 12 \\
\hline
\end{tabular}

*significant at the 0.05 level, ${ }^{* *}$ significant at the 0.001 level. OROS-MPH: Osmotic-controlled Release Oral delivery methylphenidate

Table 5. Pearson correlation between dose and K-ARS scores of each visit $(\mathrm{N}=143)$

\begin{tabular}{llll}
\hline & Dose & $\begin{array}{c}\text { Dose/ } \\
\text { Weight }\end{array}$ & $\begin{array}{c}\text { Baseline } \\
\text { K-ARS }\end{array}$ \\
\hline Dose/Weight & $0.357^{* *}$ & & \\
Baseline K-ARS & $0.275^{* *}$ & $0.233^{* *}$ & \\
Endpoint K-ARS & $0.365^{* *}$ & 0.122 & $0.391^{* *}$ \\
\hline
\end{tabular}

By Pearson correlation analysis. ${ }^{* *}$ correlation significant at the 0.001 level. K-ARS: Korean version, ADHD rating scale

\section{DISCUSSION}

This study was the first open labeled trial conducted for 12 weeks in 6 credible medical centers of Korea. The results showed differences in the optimal dose by age and symptom severity, and there were no differences by severity of adverse effects and subtypes of ADHD.

The overall mean daily dose of OROS-MPH which shows a clinical response was $30.05 \pm 12.52 \mathrm{mg} / \mathrm{d}, 0.90 \pm 0.31 \mathrm{mg} / \mathrm{kg} / \mathrm{d}$. In comparison with other Korean optimal studies, this result was higher than others. The reported dose was $0.87 \mathrm{mg} / \mathrm{kg} / \mathrm{d}$ after 3 weeks of OROS-MPH treatment without previous medication history, and dose increased with weight and age. ${ }^{21}$ In another trial, ${ }^{22}$ the optimal dose was $0.74 \mathrm{mg} / \mathrm{kg} / \mathrm{d}$ after 3 week treatment of drug naïve children. This trial was proceeded for 12 weeks, relatively longer period of time than previous Korean studies. ${ }^{21-23}$ The increase of optimal dose during titration phase is in line with 12 month follow up study that reported increased dose after 12 months of treatment and the amount of increase is greater in the first 3 months. ${ }^{24}$

The differences in optimal dosage on different ages were observed. The younger the age, much dose/weight was needed to control ADHD symptoms. Present findings are consistent with previous studies, which were thought to be influences of different pharmacokinetics by age. ${ }^{25-27}$

In contrast to previous studies that reported inattentive-predominant type was more effective with lower dose, while combined type, with greater dose, ${ }^{28,29}$ differences of optimal dosage by ADHD subtypes were not observed. This may reflect limitations on classification of subtypes based on rating scale or interviews, not on direct observation or attention test, and too small number of samples in each subtype.

Most common adverse effects were anorexia (30.95\%), insomnia (13.10\%), headache (8.93\%), in similar with other studies, ${ }^{26,30}$ none reported any severe or life-threatening effects of methylphenidate. Differences in adverse effects by dose were not observed, this is evident in previous trials. ${ }^{21,27,29}$

In interpreting the results, several limitations should be kept in mind. First, methodologically, since this was an open-label trial without placebo, the results were subject to observer bias. Also, evaluation was limited in safety and tolerability for the same reason. Second, a positive bias may have resulted from enrollment of only subjects who could tolerate OROS-MPH and experienced efficacy during the dose titration phase. Third, our sample may not reflect and generalize to unselected children in clinical practice. Children with unstable psychiatric and medical disorder were excluded from the sample. Fourth, titration phase was limited to a 12-week trial, which was the longest trial of the studies performed in Korea, however, our findings may not be generalized to long term effects of methlyphenidate.

Nevertheless, this open labeled trial is the first study to determine optimal dosage of OROS-MPH to establish its efficacy and safety in Korean children with ADHD. In the future, we will need to perform a multisite randomized controlled study for evaluating the long-term effect and tolerability of OROS-MPH in Korean subjects with ADHD.

\section{Disclosure statement}

All authors of this work would like to disclose that this study has been supported financially by Janssen Korea (Seoul, Korea).

\section{Acknowledgments}

This study was sponsored by Janssen Korea (Seoul, Korea).

\section{REFERENCES}

1. Wilens TE, Bierderman J, Spencer TJ. Attention deficit/hyperactivity disorder across the lifespan. Ann Rev Med 2002;53:113-131.

2. American Psychiatric Association. Diagnostic and Statistical Manual of Mental Disorders. Washington DC: American Psychiatric Association; 1994.

3. Barkley R, Fischer M, Edelbrock CS, Smallish L. The adolescent outcome of hyperactive children diagnosed by research criteria: I. An 8 -year prospective follow-up styudy. J Am Acad Child Adoles Psychia- 
try 1990;29:546-557.

4. Mannuzza S, Klein RG, Bessler A, Malloy P, LaPadula M. Adult outcome of hyperactive boys. Educational achievement, occupational rank, and psychiatric status. Arch Gen Psychiatry 1993;50:565-576.

5. Lilienfeld S, Waldman ID. The relation between childhood attentiondeficit hyperactivity disorder and adult antisocial behavior reexamined: the problem of heterogeneoity. Clin Psychol Rev 1990;10:699-725.

6. Greenhill LL, Pliszka S, Dulcan MK, Bernet W, Arnold V, Beitchman J, et al. Practice parameter for the use of stimulant medications in the treatment of children, adolescents, and adults. J Am Acad Child Adolesc Psychiatry 2002;41(2 Suppl):26S-49S.

7. Horwitz SM, Kelleher K, Boyce T, Jensen P, Murphy M, Perrin E, et al. Barriers to health care research for children and youth with psychosocial problems. JAMA 2002;288:1508-1512.

8. Hoagwood K, Kelleher KJ, Feil M, Corner DM. Treatment services for children with ADHD: a national perspective. J Am Acad Child Adolesc Psychiatry 2000;39:198-206.

9. Leslie LK, Weckerly J, Landsverk J, Hough RL, Hurlburt MS, Wood PA. Racial/ethnic differences in the use of psychotropic medication in high-risk children and adolescents. J Am Acad Child Adolesc Psychiatry 2003;42:1433-1442.

10. Angold A, Costello EJ, Farmer EM, Burns BJ, Erkanli A. Impaired but undiagnosed. J Am Acad Child Adolesc Psychiatry 1999;38:129-137.

11. Bussing R, Gary FA, Mills TL, Garvan CW. Parental explanatory models of ADHD: gender and cultural variations. Soc Psychiatry Psychiatr Epidemiol 2003;38:563-575.

12. Zwirs BW, Burger H, Buitelaar JK, Schulpen TW. Ethnic differences in parental detection of externalizing disorders. Eur Child Adolesc Psychiatry 2006;15:418-426.

13. Greenhill L. Attention-deficit hyperactivity disorder: the stimulants. Child Adolesc Psychiatr Clin N Am 1995;4:123-168.

14. Service Hira. 2006 Health insurance review \& assessment service. Seoul, Korea: 2006.

15. Kim YS, Cheon KA, Kim BN, Chang SA, Yoo HJ, Kim JW, et al. The reliability and validity of Kiddie-Schedule for Affective Disorders and Schizophrenia-Present and Lifetime Version-Korean version (K-SADSPL-K). Yonsei Med J 2004;45:81-89.

16. Swanson J. Remission vs. Response as the Goal of Therapy in ADHD. ADHD forum. Seoul; 2005.

17. Michelson D, Allen AJ, Busner J, Casat C, Dunn D, Kratochvil C, et al. Once-daily atomoxetine treatment for children and adolescents with attention deficit hyperactivity disorder: a randomized, placebo-controlled study. Am J Psychiatry 2002;159:1896-1901.

18. So YK, Noh JS, Kim YS, Ko SG, Koh YJ. The relaibility and validity of Korean parent and teacher ADHD rating scale. J Korean Neuropsychiatr Assoc 2002;41:283-289.
19. Kim YS, So YK, Noh JS, Choi NK, Kim SJ, Koh YJ. Normative data on the Korean ADHD Rating Scales(K-ARS) for parents and teacher. J Korean Neuropsychiatr Assoc 2003;42:352-359.

20. Barkley RA, McMurray MB, Edelbrocks CS, Robbins K. Side effects of methylphenidate in children with attention deficit hyperactivity disorder: a systemic, placebo-controlled evaluation. Pediatrics 1990;86:184192.

21. Lee SI, Hong SD, Kim SY, Kim EJ, Kim JH, Park MK, et al. Efficacy and tolerability of OROS methylphenidate in Korean children with attention-deficit/hyperactivity disorder. Prog Neuropsychopharmacol Biol Psychiatry 2007;31:210-216.

22. Shin JY, Yang JW, Jang WS, Hong SD. Prescription status and efficacy of OROS-MPH and parent perception in children with ADHD: multicenter, observational study during 4 weeks. Korean J Psychopharmacol 2007; 18:50-59.

23. Kim BS, Park EJ. An observational multi-center study for evaluation of efficacy, safety and parental satisfaction of methylphenidate-OROS in children with ADHD. Korean J Child Adolesc Psychiatry 2005;16:279285.

24. Wilens T, Pelham W, Stein M, Conners CK, Abikoff H, Atkins M, et al. ADHD treatment with once-daily OROS methylphenidate: interim 12-month results from a long-term open-label study. J Am Acad Child Adolesc Psychiatry 2003;42:424-433.

25. Wigal SB, Gupta S, Greenhill L, Posner K, Lerner M, Steinhoff K, et al. Parmacokinetics of methylphenidate in preschoolers with attentiondeficit/hyperactivity disorder. J Child Adolesc Psychopharmacol 2007; 17:153-164

26. Fallu A, Richard C, Prinzo R, Binder C. Does OROS-methylphenidate improve core symptoms and deficits in executive function? Results of an open-label trial in adults with attention deficit hyperactivity disorder. Curr Med Res Opin 2006;22:2557-2566.

27. McGough JJ, McBurnett K, Bukstein O, Wilens TE, Greenhill L, Lerner $\mathrm{M}$, et al. Once-daily OROS methylphenidate is safe and well tolerated in adolescents with attention-deficit/hyperactivity disorder. J Child Adolesc Psychopharmacol 2006;16:351-356.

28. Barkley RA, DuPaul GJ, McMurray MB. Attention deficit disorder with and without hperctivity: clinical response to three dose levels of methylphenidate. Pediatrics 1991;87:519-531.

29. Stein MA, Sarampote CS, Waldman ID, Robb AS, Conlon C, Pearl PL, et al. A dose-response study of OROS methylphenidate in children with attention-deficit/hyperactivity disorder. Pediatrics 2003;112:e404.

30. Wilens TE, McBurnett K, Bukstein O, McGough J, Greenhill L, Lerner $\mathrm{M}$, et al. Multisite controlled study of OROS methylphenidate in the treatment of adolescents with attention-deficit/hyperactivity disorder. Arch Pediatr Adolesc Med 2006;160:82-90. 